\title{
BEACH MORPHOLOGICAL CHANGES ON SENDAI COAST BY TYPHOON LIONROCK
}

\author{
Yuta Mitobe, Tohoku Gakuin University, y mitobe@mail.tohoku-gakuin.ac.jp \\ Hitoshi Tanaka, Tohoku University, hitoshi.tanaka.b7@tohoku.ac.jp \\ Akihiro Suzuki, Tohoku University, akihiro.suzuki.q8@dc.tohoku.ac.jp \\ Makoto Umeda, Tohoku University, makoto.umeda.c6@tohoku.ac.jp \\ Daisuke Komori, Tohoku University, daisuke.komori.e8@tohoku.ac.jp \\ Yoshiya Touge, Tohoku University, yoshiya.touge.a6@tohoku.ac.jp
}

\section{INTRODUCTION}

In 2016, a few typhoons attacked Tohoku Area of Japan, and one of them, named Typhoon Lionrock, approached and hit Tohoku Area from the Pacific Coast, which is the first observed typhoon to have such a course in the observation history of Japan. In order to know magnitude of the storm surge and high waves induced by the typhoon and their influence on the coastal area, field surveys were conducted on the day of the typhoon arrival and also the next day. The target of the survey was Sendai Coast, which is a part of the Pacific Coast of Tohoku Area. The coast was severely affected by the 2011 Great East Japan Earthquake Tsunami, and its effect on the beach morphology still remains according to shoreline change analysis with aerial photographs by Hoang et al. (2016). In this paper, the shoreline changes by and after the typhoon were analyzed with the aerial photographs taken in every one or two months to understand its effect on the beach processes. And the results were combined with the shoreline data after the 2011 tsunami to see the impact of the typhoon on the beach processes under the recovery from the tsunami event.

\section{FIELD SURVEY}

Based on observation soon after the typhoon and the level of the debris deposited by high waves, the maximum run up height was estimated as approximately $4 \mathrm{~m}$ from the mean sea level. It is enough lower than the height of coastal dykes; about $5 \mathrm{~m}$ from MSL before the 2011 tsunami and $7 \mathrm{~m}$ currently. Due to the higher waves, sea ward toes of container yard and a parking lot along the beach in the northern area of the coast were severely eroded as shown in Figure 1. There are two lagoons in the study area, and higher waves overtopped sand dunes in front of both lagoons. And that induced sediment transport over the sand dunes toward the lagoons behind.

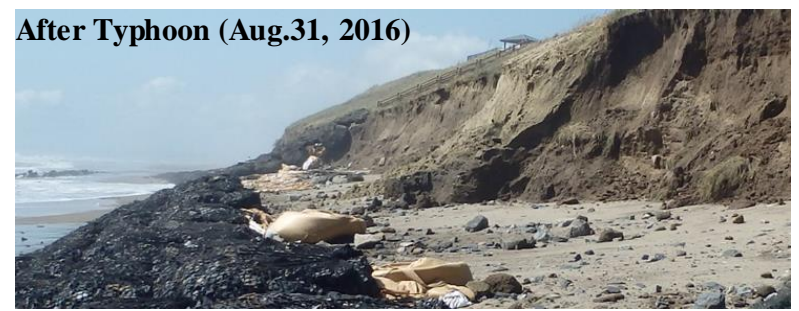

Figure 1 - Coastal Erosion Due to Typhoons in Aug., 2016

\section{AERIALPHOTO ANALYSIS}

Figure 2 (a) and (b) show shoreline positions of the northern end of the study area extracted from the aerial photographs and their changes from the position before the typhoon (July 12, 2016). The shoreline retreat by the typhoon was about $20-30 \mathrm{~m}$ in the study area, and the shoreline position reached the toes of the slopes of the container yard and the parking lot near the northern end of the study area. However, the shoreline gradually advanced and reached the position before the typhoon in one year. Especially on the right side of the Nanakita River mouth, the recovery of the shoreline was faster and only two months was needed to get back to the position before. Predominant direction of longshore sediment transport is northward, and it was partly blocked by the river flow (Pradjoko and Tanaka, 2010). That resulted in the faster recovery on the southern side of the river mouth. In the shoreline change after the 2011 tsunami, the retreat caused by the typhoon was relatively large but still much smaller than that by the 2011 tsunami itself. While the course of the typhoon was rare, the effect on the beach processes doesn't seem to be significant to induce a change of the littoral system on the coast. The shoreline changes in other area on this coast will be also discussed with related to the effect of the change due to the 2011 tsunami in the presentation.
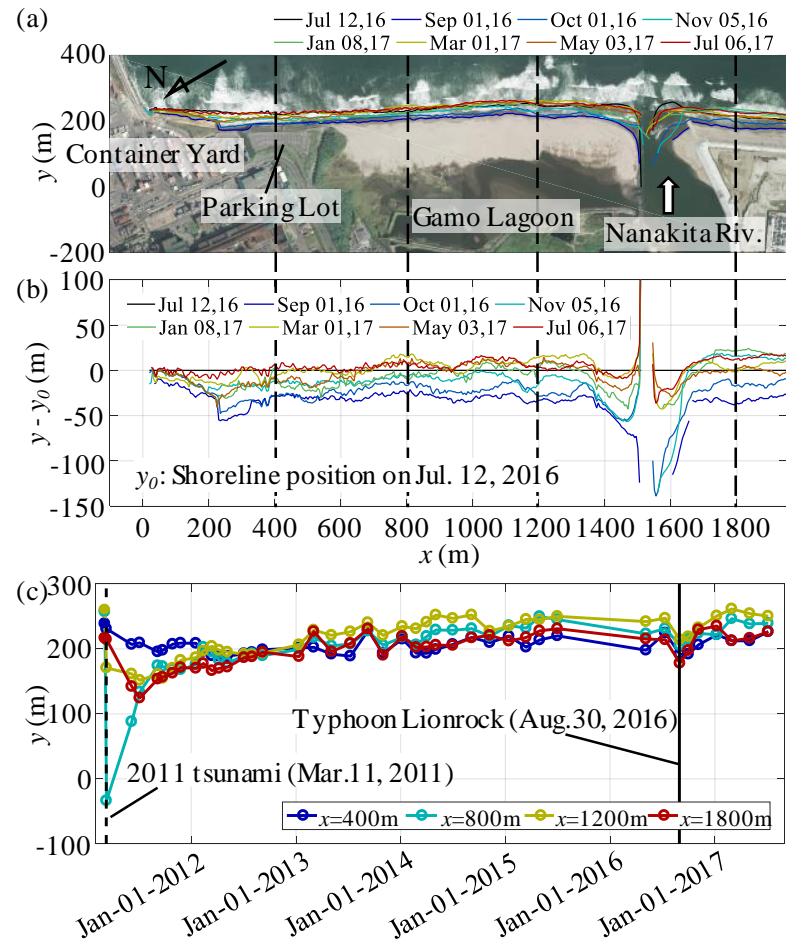

Figure 2 - Shoreline Change Analysis Based on Aerial Photographs

\section{REFERENCES}

Hoang, Tanaka, Mitobe (2016): Recovery of Littoral System on Sendai Coast after the Great East Japan Earthquake Tsunami, J. of JSCE, ser. B2 (Coast. Eng.), JSCE, Vol. 72, pp.I_769-I_774.

Pradjoko, Tanaka (2010): Aerial Photograph of Sendai Coast for Shoreline Behavior Analysis, Proc. of 32nd ICCE, ASCE, 13p. 